\title{
Systematic Review of Tranexamic Acid Adverse Reactions
}

Gioacchino Calapai ${ }^{2}$, Sebastiano Gangemi ${ }^{1}$, Carmen Mannucci ${ }^{2}$, Paola Lucia Minciullo ${ }^{1}$, Marco Casciaro ${ }^{1}$, Fabrizio Calapai ${ }^{3}$, Maria Righi ${ }^{4}$ and Michele Navarra $^{5}$

${ }^{1}$ Operative Unit of Allergy and Clinical Immunology, Department of Clinical and Experimental Medicine, University of Messina, Italy

${ }^{2}$ Department of Clinical and Experimental Medicine, University of Messina, Italy

${ }^{3}$ Centro Studi Pharma.Ca, Messina, Italy

${ }^{4}$ Department of Biomedical Sciences and Morphological and Functional Images, University of Messina, Italy

${ }^{5}$ Department of Drug Sciences and Health Products, University of Messina, Italy

*Corresponding author: Gioacchino Calapai, Department of Clinical and Experimental Medicine, University of Messina, Via Consolare Valeria 5, 98125 Messina, Italy, Tel: +39 090 2213646; Fax: +39 090 221; E-mail: gcalapai@unime.it

Received date: July 06, 2015; Accepted date: July 14, 2015; Published date: July 20, 2015

Copyright: (c) 2015 Calapai G, et al. This is an open-access article distributed under the terms of the Creative Commons Attribution License, which permits unrestricted use, distribution, and reproduction in any medium, provided the original author and source are credited.

\begin{abstract}
Background

Tranexamic acid is a synthetic lysine derivate that exerts its antifibrinolytic effect by reversible blocking lysine binding sites on plasminogen preventing fibrin degradation. It is widely used for haemorrhage or risk of haemorrhage in increased fibrinolysis or fibrinogenolysis.
\end{abstract}

\section{Aim}

The aim of our work was to review the literature regarding the best evidence on tranexamic adverse reactions and to describe them according to the apparatus involved.

\section{Methods}

The literature was searched for publications on tranexamic acid adverse reactions, adverse events, using MEDLINE, Scopus, Embase, Web of Science and Google Scholar.

\section{Results}

In the light of the results, seems to be clear that tranexamic acid causes several adverse reactions involving different apparatus. Hypersensitivity reactions, cerebrovascular infarction, myocardial infarction and pulmonary embolism seem to be the more common tranexamic acid adverse reactions.

\section{Conclusion}

Despite the wide use of tranexamic acid the number of cases reported for type of reaction is relatively low, thus causing a not easy understanding of mechanisms underlying the adverse reaction. Therefore, it would be appropriate to conduct epidemiological studies on a large scale in order to better understand risk factors favoring tranexamic acid adverse reactions and encourage pharmacovigilance in medical practice.

Keywords: Tranexamic acid; TXA; Adverse reaction; Pharmacovigilance

\section{Introduction}

Tranexamic acid (TXA) is a synthetic lysine amino acid derivative which reduces the dissolution of hemostatic fibrin by plasmin. TXA is a drug frequently used in various disciplines such as cardiology, neurosurgery and obstetrics and gynecology as a hemostatic agent and "fibrin sealant" [1]. TXA exerts its antifibrinolytic effects by reversible block of lysine binding sites on plasminogen, thus preventing plasmin from interacting with lysine residues on the fibrin polymer, causing subsequent fibrin degradation [2].
Native human plasminogen contains 4 to 5 lysine binding sites with low affinity for tranexamic acid $(\mathrm{Kd}=750 \mu \mathrm{mol} / \mathrm{L})$ and 1 with high affinity $(\mathrm{Kd}=1.1 \mu \mathrm{mol} / \mathrm{L})$. The high affinity lysine site of plasminogen is involved in its binding to fibrin. Saturation of the high affinity binding site with TXA displaces plasminogen from the surface of fibrin. Although plasmin may be formed by conformational changes in plasminogen, binding to and dissolution of the fibrin matrix is inhibited. TXA is seven to ten times more potent compared with the earliest antifibrinolytic agent-epsilon amino-caproic acid. TXA is widely distributed throughout the intracellular and extracellular compartments and is excreted mainly unchanged in the urine. It can be administered orally or intravenously [3]. 
Citation: Calapai G, Gangemi S, Mannucci C, Miniullo PL, Casciaro M, et al. (2015) Systematic Review of Tranexamic Acid Adverse Reactions .

Page 2 of 7

TXA is usually well tolerated and it is generally considered safe at the usual dosage. Nausea and diarrhea are the most common side effects [4], however, TXA can provoke serious adverse effects that have been poorly known by physicians. On the light of these evidences, we collected case reports on adverse reactions to TXA and we ordered and listed them according the affected system or apparatus with the aim to purchase to physicians a further point of view on TXA toxicity useful for a better management of this drug.

\section{Materials and Methods}

References have been reviewed on MEDLINE, Scopus, Embase, Web of Science and Google Scholar. Keywords (alone or combined) used were: tranexamic acid, adverse reaction, adverse event, side effects, safety profile, toxicity. To ensure the widest possible search, no language filters were applied. We have reviewed and reported a feature of case reports regarding TXA adverse reactions.

Only reports describing cases or case series reporting descriptions of adverse reactions to TXA were considered for this systematic review. Systematic collection of reports was operated according to the following definition of adverse drug reaction: "A response to a drug that is noxious and unintended and occurs at doses normally used in man for the prophylaxis, diagnosis or therapy of disease, or for modification of physiological function (WHO, 1972)" [5]. Adverse reactions reported in clinical studies, voluntary or accidental overdose cases and errors in therapy with TXA were excluded. TXA adverse reactions were listed according to the involved apparatus (Table 1).

\begin{tabular}{|c|c|c|c|c|c|}
\hline Adverse reaction & $\begin{array}{l}\text { Number of } \\
\text { Cases }\end{array}$ & $\operatorname{sex}$ & age & TXA posology & Reference \\
\hline \multirow{3}{*}{ Fixed drug eruption } & \multirow[t]{3}{*}{3} & $\mathrm{~F}$ & 39 & oral challenge test with $250 \mathrm{mg}$ & Kaku et al., 2014; \\
\hline & & $\mathrm{F}$ & 27 & $250 \mathrm{mg}$ & Hayakawa et al., 1995 \\
\hline & & $\mathrm{F}$ & 33 & 1g t.d.s & Kavanagh et al., 1993 \\
\hline Epidermal necrolysis & 1 & M & 67 & 1000 mg every 12 hours (10 days) & Pretel et al., 2013 \\
\hline Bullous eruption & 1 & $\mathrm{~F}$ & 36 & 500 mg every $8 \mathrm{~h}$ & Carrion et al., 2004 \\
\hline \multirow[t]{6}{*}{ Hypersensitivity reactions } & \multirow[t]{6}{*}{6} & M & 72 & $2.5 \mathrm{~g}$ & Lucas-Polomeni et al., 2004 \\
\hline & & M & 42 & 500 mg (before surgery) & \multirow[t]{5}{*}{ Imbesi et al., 2010} \\
\hline & & M & 27 & 500 mg (before surgery) & \\
\hline & & $\mathrm{F}$ & 58 & Skin test & \\
\hline & & $\mathrm{F}$ & 45 & $500 \mathrm{mg}$ & \\
\hline & & $\mathrm{F}$ & 60 & $500 \mathrm{mg}$ & \\
\hline \multirow[t]{4}{*}{ Pulmonary embolism } & \multirow[t]{4}{*}{4} & $\mathrm{~F}$ & 47 & $\begin{array}{l}1 \mathrm{~g} \text { three times a } \\
\text { day for } 3-4 \text { days }\end{array}$ & Salam et al., 2013 \\
\hline & & $\mathrm{F}$ & 59 & 400 mg daily (6 months) & Krivokuca et al., 2011 \\
\hline & & $\mathrm{F}$ & 62 & $2.4 \mathrm{~g}$ daily ( 3 days) & Woo et al., 1989 \\
\hline & & M & 29 & $1.5 \mathrm{~g}$ twice a day (5-6 months) & Taparia et al., 2002 \\
\hline Deep vein thrombosis & 1 & M & 83 & $1.5 \mathrm{~g}$ per day (16 months) & Endo et al., 1988 \\
\hline \multirow[t]{5}{*}{ Myocardial infarction } & \multirow[t]{5}{*}{5} & M & 60 & $1 \mathrm{~g}$ & Mandal et al., 2005 \\
\hline & & M & 77 & $1 \mathrm{~g}$ & Mekontso-Dessap et al., 2002 \\
\hline & & $\mathrm{F}$ & 42 & $\begin{array}{l}3 \mathrm{~g} \text { daily }+ \text { ethinylestradiol, } 20 \mathrm{mcg} \text {, and } \\
\text { gestodene, } 75 \mathrm{mcg}(2 \text { months })\end{array}$ & lacobellis and lacobellis, 2004 \\
\hline & & $\mathrm{F}$ & 28 & $1 \mathrm{~g}$ daily (1 week) & Sirker et al., 2008 \\
\hline & & $\mathrm{F}$ & 41 & $\begin{array}{l}500 \mathrm{mg} \text { TXA }+ \text { mefenamic acid } 250 \mathrm{mg} \\
\text { (every } 5 \text { days from the onset of every } \\
\text { menstrual period, in the last } 2 \text { years) }\end{array}$ & Gupta et al., 2013 \\
\hline \multirow[t]{3}{*}{ Cerebrovascular infarction } & \multirow[t]{3}{*}{6} & $\mathrm{~F}$ & 31 & $3-4.5 \mathrm{~g} /$ day & \multirow[t]{2}{*}{ Rydin et al. 1976, } \\
\hline & & $\mathrm{F}$ & 32 & $\begin{array}{l}0.5-1 \mathrm{~g} \text { (during menstrual bleeding, } 12 \\
\text { months) }\end{array}$ & \\
\hline & & $\mathrm{F}$ & 46 & 1g (3 days) & Jerico-Pascual and Gallego Cullere, 2008 \\
\hline
\end{tabular}


Page 3 of 7

\begin{tabular}{|c|c|c|c|c|c|}
\hline & & M & 65 & $1 \mathrm{~g}$ & Brand et al., 2013 \\
\hline & & $\mathrm{F}$ & 44 & \multirow{2}{*}{500 mg daily ( 3 days) } & \multirow{2}{*}{ Nardi et al., 2011} \\
\hline & & $\mathrm{F}$ & 49 & & \\
\hline \multirow[t]{2}{*}{ Acute renal cortical necrosis } & \multirow[t]{2}{*}{2} & M & 21 & $3 g /$ day for 4 days & Odabas et al., 2001 \\
\hline & & M & 37 & $3 \mathrm{~g} /$ day for 5 days & Koo et al., 1999 \\
\hline \multirow{2}{*}{ Ligneous conjunctivitis } & \multirow{2}{*}{2} & $\mathrm{~F}$ & 70 & 750 mg/day (5 weeks) & Song et al., 2014 \\
\hline & & $\mathrm{F}$ & 25 & $3 \mathrm{~g}$ during menstrual bleeding (12 months) & Diamond et al., 1991 \\
\hline \multirow{3}{*}{ Seizure } & \multirow{3}{*}{3} & $M$ & 68 & $1 \mathrm{~g}$ (5 days) & Wang et al., 2011 \\
\hline & & M & 84 & $8 \mathrm{~g}$ (intraoperatively) & Ichikawa et al., 2011 \\
\hline & & M & 45 & $1 \mathrm{~g}$ & Samanta et al., 2013 \\
\hline
\end{tabular}

Table 1: Tranexamic acid adverse reactions

\section{Cutaneous Adverse Reactions}

Reports on cutaneous TXA adverse reactions are regarding fixed drug eruption (3 cases), epidermal necrolysis (1 case) and bullous eruptions ( 1 case).

\section{Generalized fixed drug eruption}

Fixed drug eruption (FDE) is a distinctive type of cutaneous drug reaction that recurs in the same regions upon re-exposure to the offending drug. It appears as a single or a small number of red or violaceous plaques that resolve leaving post inflammatory hyperpigmentation [6]. All the three cases of fixed eruption following TXA intake are presented by women aging between 27-39 years. In one case, a Japanese woman had previously experienced repeated episodes of erythema and postinflammatory pigmentation on the back after taking drugs containing TXA. The oral challenge test with 250 mg of TXA resulted in a severe flare-up with numerous generalized new eruptions [7]. Hayakawa et al., reported a case of fixed drug eruption due to TXA in a woman that had used a toothpaste containing TXA for a long period without any adverse reaction. She developed an itching sensation accompanied by macular erythema on her hands and feet about 4 hours after taking TXA 250mg and mequitazine $3 \mathrm{mg}$ to treat itchy eruptions on her face. Both open application test with TXA 50\%pet on the affected region and oral provocation test with TXA $25 \mathrm{mg}$ showed positive reaction [8]. The third case describes a woman in whom TXA, used to treat a persistent microscopic haematuria, was previously well tolerated for 8 years. She developed a patchy, itchy rash and blisters which started on the hands and progressively involved the trunk and limbs. The eruptions resolved within days after TXA was discontinued. Desensitization with very low doses of TXA was attempted with negative results [9].

\section{Epidermal necrolysis}

Toxic epidermal necrolysis (TEN) is a severe, rare, episodic, acute mucocutaneous exfoliation described as a burn-like lesion, causally related to a great variety of medications. Pathogenesis of TEN is unclear, but it is considered expression of delayed hypersensitivity $[10,11]$.
Pretel et al., described a case of a 67-year-old male with an acute rectal bleeding was treated with TXA $1000 \mathrm{mg}$ every 8 hours. Ten days after treatment with TXA began, a purplish macular rash appeared over the patient's trunk. During the days the lesions extended and became confluent with blisters and epidermal necrosis, also involving multiple mucosal surfaces. TXA was withdrawn and prednisone therapy was started with resolution of skin lesions. The diagnosis of toxic epidermal necrolysis was confirmed by skin biopsy. However, despite benign resolution of TEN, the patient died after 2 weeks because of acute renal failure, respiratory infection and multiorgan failure [12].

Another report described the case of a 36-years old woman who developed pruritic and firm vesicle-bullous lesion tense to palpation and irregularly distributed on the lateral surfaces of the thorax, abdomen and right axilla and the flexor surfaces of forearms a few hours later treatment with TXA $500 \mathrm{mg}$ iv every 8 hours was started. The patient had been taking other medications for a necrotichemorrhagic pancreatitis, however, TXA was suspected as the culprit drug of the lesions because of a close temporal relationship between the appearance of the reaction and administration of the drug. The lesions resolved completely three days after TXA discontinuation and treatment with dexchlorpheniramine [13].

\section{Hypersensitivity Reactions}

Lucas-Polomeni et al., reported a case of anaphylactic shock after TXA administration in a 72-year-old male patient which was scheduled for coronary artery bypass graft surgery. Induction of anaesthesia was uneventful. Five minutes following bolus infusion of TXA, the patient presented clinical signs consistent with anaphylactic shock. The cutaneous tests performed for all the drugs used for anaesthesia and for latex were negative, the prick-test with TXA was positive. Several weeks later, the patient underwent surgery with a similar anaesthetic regimen and the clinical course was uneventful [14].

A case series of hypersensitivity reactions caused by TXA was described by researchers of our group in a retrospective study, based on analysis of data from patients with previous adverse drug reactions (ADRs). Five patients presented a reaction to TXA: four of them (two males and two females) had a history of TXA hypersensitivity 
reactions and one female showed a positive response to an intradermal challenge with TXA. Two patients were treated with intramuscular TXA $500 \mathrm{mg}$ and presented one widespread itching, facial and/or arms oedema and difficult breathing, the other urticaria-angioedema episode associated to breathlessness. The other two patients presented itching maculopapular lesions located on trunk and legs one and generalized urticaria and facial angioedema the other. The last patient with a multidrug hypersensitivity presented a positive intradermal test to TXA. Two of these patients underwent oral challenge test to the alternative antihemorrhagic drug (etamsylate), without reaction [15].

\section{Thromboembolic events}

TXA is used for the treatment of various types of bleeding, including menorrhagia, haematuria, surgical procedures and trauma. However, in certain situations this drug may expose patients to the risk of thrombosis. Moreover, risk of thromboembolism may be higher without the haemodilution associated with severe bleeding. Several reports of thrombotic events have been attributed to TXA.

\section{Pulmonary embolism}

Pulmonary embolism (PE) is a common and life-threatening condition due to the tendency towards early recurrence of pulmonary emboli which may lead to right ventricular failure [16]. Four cases of $\mathrm{PE}$ associated with TXA administration at different dosage ranging from 3 to $24 \mathrm{~g} /$ day for prolonged period in three cases and for few days in one case, have been reported. Cases were describing three women and one man treated with TXA in which TXA withdrawn and its substitution with anticoagulant therapy resolved the clinical feature [17-20].

\section{Deep-vein thrombosis}

Endo et al., reported a case of an 83-year-old man diagnosed for chronic idiopathic thrombocytopenic purpura that had developed a hematoma on his back after trauma. He was treated surgically and with TXA (1.5 g per day). After 16 months, he presented gait disturbance and a reddish swelling of the right thigh associated with increase of $\beta$-thromboglobulin and platelet factor and decrease of plasmin activity. Diagnosis of deep-vein thrombosis was confirmed by venography and computed tomographyc scanning [21].

\section{Myocardial infarction}

Some cases of myocardial infarction have been reported after treatment with TXA. In one case, one hour after administration of $1 \mathrm{~g}$ TXA in a man with severe rectal bleeding prior to undergoing emergency laparotomy, the patient developed severe retrosternal chest pain with profuse sweating. Anteroseptal myocardial infarction was diagnosed. Coronary angiography revealed occlusion of the right coronary artery. The patient's symptoms resolved on medical therapy and coronary intervention was not required [22].

Another case reported a 77-year-old woman admitted to the intensive care unit following the sudden onset of retrosternal chest pain with shortness of breath. TXA had started a week before admission because of intermittent haemoptysis related to her tuberculosis sequellae. The initial dosage of $500 \mathrm{mg}$ bid was doubled 2 days before admission because of recurrent haemoptysis. Transthoracic echocardiography revealed an akinetic motion of the left ventricle apex. TXA was withdrawn and the patient was treated.
ECG signs resolved rapidly and percutaneous coronary intervention was not necessary [23].

Another case involved a 42-year-old woman who was taking TXA in association with an oral contraceptive pill, as treatment for menorrhagia. In this case the adverse reaction was characterized by coronary ulcerated plaque and acute myocardial infarction [24].

Sirker et al., described a case of acute myocardial infarction in a woman diagnosed at 21 years for desmopressin-responsive platelet dysfunction. She kept to use intranasal desmopressin frequently at home for nose bleeds. When she was 28 years old, since underwent elective shoulder arthroscopy and decompression for tendon damage, she received a single dose of intravenous desmopressin $1 \mathrm{~h}$ prior to the procedure and oral TXA 1 g q.d.s. for 1 week thereafter. Three days after completion of therapy, she developed dull chest pain at rest and her electrocardiogram indicated an acute inferior ST segment elevation myocardial infarction due to the occlusion in a small distal branch of her right coronary artery. She was given Aspirin $300 \mathrm{mg}$ orally and underwent emergency cardiac catheterization. The Authors concluded for an association between myocardial infarction and TXA because the timing in the patient's case was much more suggestive of a link to TXA rather than desmopressin [25].

Gupta et al., reported another case an acute myocardial infarction in a 41-year-old hypertensive woman possibly because of an intake of a combination of TXA and mefenamic acid for dysmenorrhoea and menorrhagia [26].

In the cases reported by Mandal, Mekontso-Dessap et al. and Iacobellis et al. $[23,24]$ the patients had additional risk factors for arterial thrombosis. In contrast, in the cases reported by Sirker et al. and Gupta et al. $[25,26]$, the patients had an apparently low risk for arterial thrombosis.

\section{Cerebrovascular infarction}

Rydin et al., reported two cases of intracranial arterial thrombosis, occurred in young women after TXA administration. The first case reported of a 31 years old woman bearing uterine myomas with menorrhagia, resulting in severe anemia treated for one year with TXA (3-4.5 g/day), during the days of blood loss. One day after the beginning of TXA administration the woman experienced a transitory weakness of her left hand. She continued TXA administration and one week later she presented paresis of her left arm and leg with impaired skin sensibility. A right-sided cerebral lesion was diagnosed at EEG with clear regression within three days. Carotid angiography revealed circulatory impairment within one of the posterior peripheral branches of the right middle cerebral artery. The second case regards a 32-year old woman who had been taking TXA (0.5 -1 g), during menstrual period for about one year. She developed a left-sided hemiparesis and a homonymous hemianopia. Carotid angiography revealed thrombosis of the right posterior cerebral artery. Three months after, some symptoms were still persisting). In neither case the Authors found evidence of any underlying disease that have been thrombogenic [27].

Two Authors' groups reported the appearance of simultaneous PE and cerebrovascular accident (CVA) in the presence of patent foramen ovale after TXA administration [28,29]. The first is a case of a 46-yearold woman without thromboembolic risk factors who developed an ischemic CVA after three days of oral TXA for the treatment of menorrhagia [28]. In the second report a 65-year-old male with a previously undiagnosed patent foramen ovale, presented pulmonary 
emboli and cerebrovascular infarction after synchronous bilateral total knee replacement during which 1 g TXA was administered intravenously. Thrombolytic therapy was started with low molecular weight heparin. All the neurological signs resolving over the following 5 days. At 4 months follow-up, the patient reported mild subjective residual dysarthria [29].

Nardi et al., reported two cases of acute stroke following TXA administration in young women carrying heterozygosity for methylene-tetrahydrofolate reductase (MTHFR) C677T. The first patient, a 44-year-old woman, presented left hemiplegia, mild dysarthria and anosognosi, the second patient, a 49-year-old woman, developed aphasia and right emiplegia. The two ischemic events were diagnosed by neuroimaging. In both cases TXA (500 mg oral/daily) was administered for three days for bleeding gynecological disorders. The Authors concluded that a possible synergic effect of plasminogen inhibitor and heterozygosis for MTHFR C677T could be on the basis of pathogenetic mechanism leading to ischaemic stroke in young people [30].

\section{Uterine thrombosis}

Uterine leiomyoma is the most common gynecologic cause for menorrhagia along side dysfunctional uterine bleeding [31-33]. Necrosis in uterine leiomyomas was associated with pregnancy, and progestogen or oral contraceptives [34-36].

Women with menorrhagia have increased levels of plasminogen activators in the endometrium and TXA is commonly prescribed worldwide to women with menorrhagia, including those with fibroids [37]. Ip et al. reported a large scale clinic pathologic study investigating on the association of TXA and necrosis and thrombosis in uterine leiomyomas. One hundred forty-seven patients treated with TXA were investigated. Infarct-type necrosis was observed in the leiomyomas of 38 patients, 22 of whom had taken TXA (15\%) (odds ratio=3.60; 95\% confidence interval: $1.83-6.07 ; \mathrm{P}=0.0003)$. Eleven of the 22 cases of drug-induced necrotic leiomyoma (50\%) also showed intralesional thrombus formation, and 4 of them showed organization of the thrombi [37].

\section{Acute renal cortical necrosis}

Acute renal cortical necrosis represents a relatively rare cause of acute renal failure in which a diffuse necrosis of renal cortical structure is observed histologically [38]. Two cases of acute renal cortical necrosis have been reported in literature (Koo et al, Obadas et al). Koo et al. reported a case of 37 years-old man with a medical history of pulmonary tuberculosis with sequelae of bronchiectasis which was diagnosed of acute renal cortical necrosis with glomerular thrombosis, six days after intravenous TXA administration ( $3 \mathrm{~g} /$ day) prescribed for 5 days for haemoptysis. Renal biopsy showed infarction, with fibrin thrombi in intraglomerular capillaries and arterioles. He was treated with haemodialysis for 2 weeks and his renal function slowly improved reaching the normality in 3 weeks [39].

The other case reports on a 21-year-old man suffering of haemophilia A. Because of an epistaxis attack he was treated with TXA $3 \mathrm{~g} /$ day for 4 days. After 3 days of TXA administration appeared oligoanuria and azotaemia and after successive few days increase of serum creatinine, therefore he was treated by haemodialysis for 3 weeks. Urine output decreased below $20 \mathrm{cc} /$ day and did not increase again. Renal angiography allowed diagnosis of renal cortical necrosis [40].
In both patients there were no known risk factors for acute renal cortical necrosis.

\section{Ocular Adverse Reactions}

\section{Retinal artery occlusion}

Parson et al., described a retinal artery occlusion in a 57 year old woman diagnosed for myelogenous leukemia treated with TXA (750 $\mathrm{mg}$, twice daily) given for hemorrhagic cystitis caused by cyclophosphamide. Five days later, she reported blurry vision. A scotoma above fixation in the right eyes was confirmed by Amsler grid test. Oftalmoscopy of the right eye, disclosed a tertiary branch retinal artery occlusion. TXA was suspected as the trigger factor leading to the arterial occlusion [41].

\section{Ligneous conjunctivitis}

Ligneous conjunctivitis is a rare form of membranous conjunctivitis of unknown aetiology $[42,43]$. The disease classically presents with the appearance of thickened, 'wood-like' membranes covering the tarsal conjunctiva. Other mucus membranes may also become involved, including the middle ear, buccal mucosa, nasopharynx, larynx, vocal cords, trachea, vagina, and cervix [43-46]. Two cases of ligneous conjunctivitis associated with TXA use were described.

Diamond et al., reported a case of a 25 -year-old Caucasian woman diagnosed with Epstein's syndrome and in treatment with peritoneal dialysis and with TXA 3g/day to control menorrhagia. The woman referred to Bristol Eyes Hospital for a nine months history of ocular irritation and sticky discharge. She had swollen eyelids with thickened, pale membranes adherent to the tarsal conjunctiva that was hyperaemic and haemorrhagic. Topical ocular treatment with different drugs did not induce notable improvement. She also presented peritoneal protein loss and gingiva involvement. All systemic drug treatment was discontinued and within five weeks the conjunctival membranes disappeared, protein loss resolved and her gingival returned to normal health. After the reintroduction of TXA treatment the lesions began to form again. Discontinuation again resulted in resolution [47].

Has been recently reported a case of TXA-induced ligneous conjunctivitis with reversible hypoplasminogenaemia by Song et al. A 70 -year-old woman with a gastric ulcer was treated with oral TXA $(750 \mathrm{mg} /$ day). After 5 weeks of treatment, she presented a bilateral pale yellow pseudomembrane on the palpebral conjunctivae. Haematological analysis showed hypoplasminogenaemia. A diagnosis of ligneous conjunctivitis was made, and treatment with daily topical cyclosporine was initiated without significant improvement. After TXA discontinuation the pseudomembranes regressed and the serum plasminogen level returned to the normal range. Since the relationship between hypoplasminogenaemia and ligneous conjunctivitis has been firmly established in the past. 1 and in the second report the hypoplasminogenaemia resolved after TXA discontinuation, the Authors concluded that the antifibrinolytic property of this drug may lead to the development of this type of conjunctivitis in some patients [48].

\section{Seizures}

Generalized convulsion is a very rare, but serious adverse effect of TXA. Wang et al., reported a case of a 68-year-old man who 
experienced a single convulsive seizure resulted in transient hyperammonemia during intravenously treatment with TXA ( $1 \mathrm{~g}$ four times daily) for persistent hemoptysis. Five days after the beginning of the therapy, clonic convulsions that progressed to generalized seizures were noted. Elevated ammonia level was found. No further seizures occurred after immediate discontinuation of the drug. The ammonia level on the following day normalized even without any treatment for the hyperammonemia. No other cause of seizures was found [49].

Another case reported of postoperative repeated generalized convulsive seizure in an 84-year-old man with hypertension associated with hyperaldosteronism and chronic interstitial nephritis who underwent an aortic valve replacement. The seizures were likely due to a total dose of $8 \mathrm{~g}$ of TXA administered intraoperatively. Possible mechanisms of TXA-induced seizures include blockage of inhibitory cortical y-aminobutyric acid-A receptors [50].

Global left and right ventricular dysfunction after TXA injection in a patient of polytrauma, has been reported by Samanta et al. A 45year-old polytrauma patient presented with profuse bleeding from external wounds, developed within 20 min after injection with TXA 1 $\mathrm{g}$, an adverse reaction characterized by dyspnea, chest tightness, palpitation, tachycardia, itching in the left hand and developed rashes (urticaria) over his upper limb and chest. On auscultation, mild bronchospasm was present. Repeat ECG showed a significant ST depression. Serial cardiac enzymes at 2, 6 and 12 th hours were within normal. Transthoracic echocardiography examination at second and 12 th hours revealed global left and right ventricular hypokinesia. Coronary angiography performed on the following day showed no significant coronary artery disease. Serum tryptase (mast cell) and immunoglobin E level were found positive for allergic reaction. The Authors hypothesized that spasm of the left and right coronary arteries on exposure to TXA was the cause of global ventricular dysfunction, which reversed spontaneously [51].

\section{Discussion}

TXA is a synthetic lysine analogue that blocks the lysine binding sites on plasminogen competitively and it is an effective fibrinolytic inhibitor. The serum half-life is approximately $1-2 \mathrm{~h}$, but the inhibitory effect lasts for 7-8 h.

TXA has been indicated in various conditions, including menorrhagia, gastrointestinal bleeding, post-tonsillectomy, genitourinary bleeding and has also been used effectively in patients with haemophilia and von Willebrand's disease [52].

The side-effects and the complications include, nasal stuffiness, conjunctival suffusion $[53,54]$ and abdominal discomfort, nausea and diarrhoea. Most of them have been confirmed through two large scale studies. One is a randomised controlled trial undertaken involving 20211 adult trauma patients with, or at risk of, significant bleeding randomly assigned to either TXA or matching placebo, showing that TXA safely reduced the risk of death [55]. In the second, the use of TXA in combat injury was investigated with the aim to assess its effects on total blood product use, thromboembolic complications, and mortality. The timing and magnitude of survival benefit of TXA suggested that a beneficial mechanism other than hemostasis may be present. Thus indicating that, beyond hemostasis, attenuation of the inflammatory response could play a role in the survival benefit associated with TXA [56].
The aim of this review was to highlight the attention on TXA adverse reactions. From analysis of case reports, reported in our review, it appears that TXA administration can be burdened by several adverse reactions, that we have reported in Table 1 , according to the apparatus involved. Among the cases of TXA adverse reactions, hypersensitivity reactions (6 cases), cerebrovascular infarction (6 cases), myocardial infarction (5 cases) and pulmonary embolism (4 cases), seem to be the more frequent (Table 1).

Despite the wide use of TXA the number of cases reported for type of reaction is relatively low, thus causing a not easy understanding of mechanisms underlying the adverse. Therefore, it would be appropriate to conduct epidemiological studies on a large scale in order to better understand risk factors favoring TXA adverse reactions and encourage pharmacovigilance in medical practice.

\section{References:}

1. Bhat A, Bhowmik DM, Vibha D, Dogra M, Agarwal SK (2014) Tranexamic acid overdosage-induced generalized seizure in renal failure. Saudi J Kidney Dis Transpl 25: 130-132.

2. Wellington K, Wagstaff AJ (2003) Tranexamic acid: a review of its use in the management of menorrhagia. Drugs 63: 1417-1433.

3. Nilsson IM (1980) Clinical pharmacology of aminocaproic and tranexamic acids. J Clin Pathol Suppl (R Coll Pathol) 14: 41-47.

4. Dunn CJ, Goa KL (1999) Tranexamic acid: a review of its use in surgery and other indications. Drugs 57: 1005-1032.

5. [No authors listed] (1972) International drug monitoring: the role of national centres. Report of a WHO meeting. World Health Organ Tech Rep Ser 498: 1-25.

6. Shiohara $\mathrm{T}$ (2009) Fixed drug eruption: pathogenesis and diagnostic tests Curr Opin Allergy Clin Immunol 9: 316-321.

7. Kaku Y, Ito T, Kudo K, Kido-Nakahara M, Nakahara T, et al. (2014) Generalized fixed drug eruption induced by tranexamic acid. Eur J Dermatol 24: 408-409.

8. Hayakawa R, Suzuki M, Ogino Y (1995) Fixed drug eruption due to tranexamic acid. Environ Dermatol 2: 100-104.

9. Kavanagh GM, Sansom JE, Harrison P, Warwick JA, Peachey RD (1993) Tranexamic acid (Cyklokapron)-induced fixed-drug eruption. $\mathrm{Br} \mathrm{J}$ Dermatol 128: 229-230.

10. Tartarone A, Lerose R (2010) Stevens-Johnson syndrome and toxic epidermal necrolysis: what do we know? Ther Drug Monit 32: 669-672.

11. Mahar PD, Wasiak J, Hii B, Cleland H, Watters DA, et al. (2014) A systematic review of the management and outcome of toxic epidermal necrolysis treated in burns centres. Burns 40: 1245-1254.

12. Pretel Irazabal M, Marques Martin L, Aguado Gil L, Idoate Gastearena MA (2013) Tranexamic acid-induced toxic epidermal necrolysis. Ann Pharmacother 47: e16.

13. Carri $\tilde{A}^{3} n-C a r r i \tilde{A}^{3} n$ C, del Pozo-Losada J, Gutierrez-Ramos R, de LucasLaguna R, GarcÃa-Diaz B, et al. (1994) Bullous eruption induced by tranexamic acid. Ann Pharmacother 28: 1305-1306.

14. Lucas-Polomeni MM, Delaval Y, Menestret P, Delaval P, Ecoffey C (2004) [A case of anaphylactic shock with tranexamique acid (Exacyl)]. Ann Fr Anesth Reanim 23: 607-609.

15. Imbesi S, Nettis E, Minciullo PL, Di Leo E, Saija A, et al. (2010) Hypersensitivity to tranexamic acid: a wide spectrum of adverse reactions. Pharm World Sci 32: 416-419.

16. Chalikias G, Konstantinides S (2014) Acute phase treatment of pulmonary embolism. Curr Vasc Pharmacol 12: 393-400.

17. Salam A, King C, Orhan O, Mak V (2013) The great deception: tranexamic acid and extensive pulmonary emboli. BMJ Case Rep 2013.

18. Krivokuca I, Lammers JW (2011) Recurrent pulmonary embolism associated with a hemostatic drug: tranexamic acid. Clin Appl Thromb Hemost 17: 106-107. 
19. Woo KS, Tse LK, Woo JL, Vallance-Owen J (1989) Massive pulmonary thromboembolism after tranexamic acid antifibrinolytic therapy. Br J Clin Pract 43: 465-466.

20. Taparia M, Cordingley FT, Leahy MF (2002) Pulmonary embolism associated with tranexamic acid in severe acquired haemophilia. Eur J Haematol 68: 307-309.

21. Endo Y, Nishimura S, Miura A (1988) Deep-vein thrombosis induced by tranexamic acid in idiopathic thrombocytopenic purpura. JAMA 259: 3561-3562.

22. Amit Mandal KJ, Missouris CG (2005) Tranexamic acid and acute myocardial infarction. Br J Cardiol 12: 306-307.

23. Mekontso-Dessap A, Collet JP, Lebrun-Vignes B, Soubri命 C, Thomas D, et al. (2002) Acute myocardial infarction after oral tranexamic acid treatment initiation. Int J Cardiol 83: 267-268.

24. Iacobellis G, Iacobellis G (2004) Combined treatment with tranexamic acid and oral contraceptive pill causes coronary ulcerated plaque and acute myocardial infarction. Cardiovasc Drugs Ther 18: 239-240.

25. Sirker A, Malik N, Bellamy M, Laffan MA (2008) Acute myocardial infarction following tranexamic acid use in a low cardiovascular risk setting. Br J Haematol 141: 907-908.

26. Gupta PN, Mullamalla UR, Sabin P, Vellappan P (2013) Acute MI in a young hypertensive woman: could it be due to tranexamic acid? BMJ Case Rep 2013.

27. Rydin E, Lundberg PO (1976) Letter: Tranexamic acid and intracranial thrombosis. Lancet 2: 49.

28. Jeric $\tilde{A}^{3}$-Pascual I, GÃjllego-Cullere J (2008) [Stroke, tranexamic acid and patent foramen ovale]. Rev Neurol 46: 186.

29. Bruce-Brand R, Dragomir R, Baker J, Harty J (2013) Cerebrovascular infarction following bilateral total knee arthroplasty and tranexamic acid administration. Acta Orthop Belg 79: 351-354.

30. Nardi K, Pelone G, Bartolo M, Di Ruzza MR, Storto M, et al. (2011) Ischaemic stroke following tranexamic acid in young patients carrying heterozygosity of MTHFR C677T. Ann Clin Biochem 48: 575-578.

31. Oehler MK, Rees MC (2003) Menorrhagia: an update. Acta Obstet Gynecol Scand 82: 405-422.

32. Rybo G (1991) Tranexamic acid therapy is effective treatment in heavy menstrual bleeding: clinical update on safety. Ther Adv 4: 1-8.

33. West CP, Lumsden MA (1989) Fibroids and menorrhagia. Baillieres Clin Obstet Gynaecol 3: 357-374.

34. Clement PB, Young RH, Scully RE (1989) Nontrophoblastic pathology of the female genital tract and peritoneum associated with pregnancy. Semin Diagn Pathol 6: 372-406.

35. Myles JL, Hart WR (1985) Apoplectic leiomyomas of the uterus. A clinicopathologic study of five distinctive hemorrhagic leiomyomas associated with oral contraceptive usage. Am J Surg Pathol 9: 798-805.

36. Norris HJ, Hilliard GD, Irey NS (1988) Hemorrhagic cellular leiomyomas ("apoplectic leiomyoma") of the uterus associated with pregnancy and oral contraceptives. Int J Gynecol Pathol 7: 212-224.

37. Ip PP, Lam KW, Cheung CL, Yeung MC, Pun TC, et al. (2007) Tranexamic acid-associated necrosis and intralesional thrombosis of uterine leiomyomas: a clinicopathologic study of 147 cases emphasizing the importance of drug-induced necrosis and early infarcts in leiomyomas. Am J Surg Pathol 31: 1215-1224.

38. Lake EW, Humes HD (1995) Acute renal failure including cortical necrosis. In: Massry SG, Glassock RJ, eds. Textbook of Nephrology.
39. Koo JR, Lee YK, Kim YS, Cho WY, Kim HK, et al. (1999) Acute renal cortical necrosis caused by an antifibrinolytic drug (tranexamic acid). Nephrol Dial Transplant 14: 750-752.

40. OdabaÅŸ AR, Cetinkaya R, SelÃ§uk Y, Kaya H, CoÅŸ Yun U (2001) Tranexamic-acid-induced acute renal cortical necrosis in a patient with haemophilia A. Nephrol Dial Transplant 16: 189-190.

41. Parsons MR, Merritt DR, Ramsay RC (1988) Rertinal artery occlusion associated with tranexamic acid therapy. Am J Ophthalmol 105: 688-689.

42. Schuster V, Seregard S (2003) Ligneous conjunctivitis. Surv Ophthalmol 48: 369-388.

43. Hidayat AA, Riddle PJ (1987) Ligneous conjunctivitis. A clinicopathologic study of 17 cases. Ophthalmology 94: 949-959.

44. Marcus DM, Walton D, Donshik P, Choo L, Newman RA, et al. (1990) Ligneous conjunctivitis with ear involvement. Arch Ophthalmol 108: 514-519.

45. Frimodt-Moller J (1973) Conjunctivitis ligneosa combined with a dental affection. Report of a case. Acta Ophthalmol (Copenh) 51: 34-38.

46. Rubin A, Buck D, MacDonald MR (1989) Ligneous conjunctivitis involving the cervix. Case report. Br J Obstet Gynaecol 96: 1228-1230.

47. Diamond JP, Chandna A, Williams C, Easty DL, Scully C, et al. (1991) Tranexamic acid-associated ligneous conjunctivitis with gingival and peritoneal lesions. Br J Ophthalmol 75: 753-754.

48. Song Y, Izumi N, Potts LB, Yoshida A (2014) Tranexamic acid-induced ligneous conjunctivitis with renal failure showed reversible hypoplasminogenaemia. BMJ Case Rep 2014.

49. Wang CS, Yang CJ, Chen SC, Chen HC, Huang MS (2011) Generalized convulsion resulted in hyperammonemia during treatment with tranexamic acid for hemoptysis. Ir J Med Sci 180: 761-763.

50. Ichikawa J, Kodaka M, Nishiyama K, Sato N, Kubota S, et al. (2013) A case of postoperative convulsive seizure following tranexamic acid infusion during aortic valve replacement. Masui 62: 186-189.

51. Samanta S, Jain K, Batra YK (2013) Global left and right ventricular dysfunction after tranexamic acid administration in a polytrauma patient. Ann Card Anaesth 16: 305-307.

52. Hedner U, Hirsh J, Hardner VJ (2001) Therapy with Antifibrinolytic Agents; Hemostasis and Thrombosis, 4th edn. London: Lipincott, Williams \& Wilkins.

53. Nilsson IM, Andersson L, Bjorkman SE (1966) Epsilon-aminocaproic acid (E-ACA) as a therapeutic agent based on 5 years' clinical experience. Acta Med Scand 448: 1-46.

54. Andersson L, Nilsson IM, NilÃ $\odot$ hn JE, Hedner U, Granstrand B, et al. (1965) Experimental and clinical studies on AMCA, the antifibrinolytically active isomer of p-aminomethyl cyclohexane carboxylic acid. Scand J Haematol 2: 230-247.

55. CRASH-2 trial collaborators, Shakur H, Roberts I, Bautista R, Caballero J, et al. (2010) Effects of tranexamic acid on death, vascular occlusive events, and blood transfusion in trauma patients with significant haemorrhage (CRASH-2): a randomised, placebo-controlled trial. Lancet 376: 23-32.

56. Morrison JJ, Dubose JJ, Rasmussen TE, Midwinter MJ (2012) Military Application of Tranexamic Acid in Trauma Emergency Resuscitation (MATTERs) Study. Arch Surg 147: 113-119. 